\title{
Comparison of genetic characteristics and pathogenicity of Lactococcus garvieae isolated from aquatic animals in Taiwan
}

\author{
Ming-An Tsai ${ }^{1}$, Pei-Chyi Wang ${ }^{1}$, Li-Ling Liaw ${ }^{2}$, Terutoyo Yoshida ${ }^{3}$, \\ Shih-Chu Chen ${ }^{1,4, *}$
}

\begin{abstract}
${ }^{1}$ Department of Veterinary Medicine, National Pingtung University of Science and Technology, Pingtung, Taiwan
${ }^{2}$ Bioresource Collection and Research Center, Food Industry Research and Development Institute, Hsinchu, Taiwan ${ }^{3}$ Department of Fisheries, Faculty of Agriculture, Miyazaki University, Miyazaki, Japan

${ }^{4}$ Graduate Institute of Animal Vaccine, National Pingtung University of Science and Technology, Pingtung, Taiwan
\end{abstract}

\begin{abstract}
Seventy-six Taiwanese bacterial isolates including 74 from diseased, cultured, aquatic animals (54 grey mullet Mugil cephalus, 3 basket mullet Chelon alatus, 2 tilapia Oreochromis niloticus, 1 grouper Epinephelus coioides, 2 yellowfin seabream Acanthopagrus latus, 1 Borneo mullet Chelon macrolepis, 1 bullfrog Rana catesbeiana, 1 Japanese eel Anguilla japonica, and 9 giant freshwater prawns Macrobrachium rosenbergii), 1 wild-caught seafood species (squid muscle collected from a restaurant) and 1 human isolate (from a patient with a history of consuming raw squid in the previously mentioned restaurant), all collected between 1999 and 2006, were confirmed by PCR assay to be Lactococcus garvieae. The phenotypic characterization was determined by rabbit anti-KG+ and KG- serums, and 74 of the 76 Taiwanese strains displayed a KG-phenotype. The genetic characterization was investigated by pulsed-field gel electrophoresis (PFGE). Genomic DNA was digested with restriction endonucleases Apa I and Sma I and separated by PFGE. Ten different $L$. garvieae pulsotypes were identified. Predominant pulsotypes A1a/S1a were obtained from $>96 \%$ of strains (52 of 54) from grey mullet, demonstrating a clonal dissemination of $L$. garvieae in grey mullet in Taiwan. In experimental challenges with grey mullet and tilapia, L. garvieae pulsotypes A1/S1 and A11/S11 showed higher virulence compared with other pulsotypes.
\end{abstract}

KEY WORDS: Lactococcosis · Pulsed-field gel electrophoresis · Pulsotype $\cdot$ Grey mullet · Tilapia · Giant freshwater prawn

Resale or republication not permitted without written consent of the publisher

\section{INTRODUCTION}

Lactococcus garvieae is an important Gram-positive bacterial pathogen that causes lactococcosis in a variety of marine and freshwater fishes worldwide. Besides fish, L. garvieae infection has been observed in giant freshwater prawns Macrobrachium rosenbergii (Chen et al. 2001) and mammals such as water buffalos and dairy cows (Carvalho et al. 1997, Devriese et al. 1999). Although this pathogen has a low virulence in human infection, the number of case reports of $L$. garvieae infection in humans is increas- ing (Fefer et al. 1998, James et al. 2000, Vinh et al. 2006, Wang et al. 2007, Li et al. 2008). Therefore, $L$. garvieae is a zoonotic pathogen of increasing clinical significance in animals and humans (Elliott et al. 1991, Vela et al. 2000).

When bacterial strains are compared based on their geographical origin, host and year of isolation, pulsed-field gel electrophoresis (PFGE) is a conventional means of discriminating between genetic variants (Tenover et al. 1995, Shimahara et al. 2009). When determining the epidemiological relationships PFGE is a highly effective approach for strain typing. 
A previous study examined the phenotypic and genetic characteristics of 84 isolates of Lactococcus garvieae from different sources and countries to elucidate the epidemiological relationship between historic and recent outbreaks of lactococcosis (Vela et al. 2000). Genotypic characterization by PFGE was also utilized for strain typing of $L$. garvieae from fish and terrestrial animals from Japan and Europe (Kawanishi et al. 2005, 2006). The genetic variability of $L$. garvieae and the epidemiology of lactococcosis in Taiwan have seldom been investigated.

In Taiwan, lactococcosis outbreaks have occurred in grey mullet Mugil cephalus and giant freshwater prawns Macrobrachium rosenbergii (Chen et al. 2001, 2002). Endemic infection normally occurs during the summer and contributes significantly to decreased production in grey mullet and giant freshwater prawn farming (Chen et al. 2001, 2002). Lactococcosis has also been observed recently in other aquatic animals, including tilapia Oreochromis niloticus, basket mullet Chelon alatus, yellowfin seabream Acanthopagrus latus, Japanese eels Anguilla japonica and bullfrogs Rana catesbeiana in Taiwan (Yunlin County Animal Disease Control Center 2006). However, to our knowledge, the epidemiological relationship among the outbreaks of lactococcosis in grey mullet and other aquatic animals in Taiwan has not been investigated. This study investigated the genetic relationship of different Lactococcus garvieae strains obtained from 1999 to 2006 in various diseased aquatic animals in Taiwan. Moreover, pathogenicity of pulsotype variants of $L$. garvieae was determined.

\section{MATERIALS AND METHODS}

\section{Bacterial strains}

The sources yielding Lactococcus garvieae are listed in Table 1. Seventy-six strains were isolated from diseased grey mullet $(\mathrm{n}=54)$, basket mullet $(\mathrm{n}=3)$, Borneo mullet Chelon macrolepis $(\mathrm{n}=1)$, tilapia $(\mathrm{n}=2)$, grouper Epinephelus coioides $(\mathrm{n}=$ $1)$, yellowfin seabream $(n=2)$, Japanese eel $(n=1)$, bullfrog ( $\mathrm{n}=1)$ and giant freshwater prawns $(\mathrm{n}=9)$ in Taiwan. Additionally, L. garvieae strains isolated from seafood (raw squid muscle) sampled from a restaurant in Taoyuan, Taiwan, and from blood of a patient with gastrointestinal disease (the patient had a history of consuming raw squid in the aforementioned restaurant) in Taiwan were also included (Wang et al. 2007). L. garvieae strains isolated from yellowtail Seriola quinqueradiata $(\mathrm{n}=3)$ in Japan were also included in the analyses as these represented geographically distinct strains with different capsular types and were used for pathogenicity comparisons with local strains in challenge experiments. L. garvieae strain ATCC 43921 from the American Type Culture Collection was used as a reference strain and subjected to phenotypic and genetic analysis by the same methods. The strains were cultured on Todd Hewitt agar (THA, Difco), blood agar (tryptic soy agar [TSA, Difco] supplemented with 5\% goat blood) and Todd Hewitt broth (THB, Difco) at $25^{\circ} \mathrm{C}$ with moderate shaking at $125 \mathrm{rpm}$ for $24 \mathrm{~h}$. The isolates were speciated based on Gram staining and PCR. Additionally, the rabbit antiserums for both $\mathrm{KG}+$ cells and a highly capsulated strain C1 (KG- phenotype cells) as described by Yoshida et al. (1996) were used for phenotyping. Bacterial strains were harvested, washed twice with $0.85 \%$ saline and killed by adding formaldehyde to a final concentration of $0.3 \%$ at $4^{\circ} \mathrm{C}$ for $24 \mathrm{~h}$. The bacteria were washed 3 times with saline and adjusted to an optical density of 1.0 at $610 \mathrm{~nm}$ for slide agglutination. One drop of antiserum diluted 1:10 was added to each of the bacterial suspensions and incubated at room temperature for $5 \mathrm{~min}$.

\section{PCR}

All strains used in this study were confirmed as Lactococcus garvieae based on PCR with speciesspecific primers, pLG-1 (5'-CAT AAC AAT GAG AAT CGC-3') and pLG-2 (5'-GCA CCC TCG CGG GTT G-3'), as described by Zlotkin et al. (1998). The primer synthesis was carried out by MDBio. DNA was extracted from L. garvieae and other bacteria by using the method of Chen et al. (2001). Overnight cultures $(10 \mathrm{ml})$ were then isolated by phenol/chloroform extraction, followed by precipitation with isopropanol (Chen et al. 2001). Next, the DNA was dissolved into $100 \mu \mathrm{l}$ of sterilized distilled water and stored at $-20^{\circ} \mathrm{C}$ until use. PCR was performed on a thermal cycler (Biorad) with reaction mixtures containing $50 \mathrm{mM} \mathrm{KCl}, 10 \mathrm{mM}$ Tris- $\mathrm{HCl}$ (pH 8.3), $1.5 \mathrm{mM}$ $\mathrm{MgCl}_{2}, 200 \mu \mathrm{M}$ deoxynucleoside triphosphate, $10 \mu \mathrm{M}$ each primer, $2 \mu \mathrm{l}$ (50 ng) of template DNA and $0.75 \mathrm{U}$ of Blend Taq ${ }^{\circledR}$ DNA polymerase (Toyobo) to a final volume of $25 \mu \mathrm{l}$. Cycling conditions were as given in Zlotkin et al. (1998). Finally, the PCR amplified products were resolved in $1 \%$ agarose gel by electrophoresis. 


\section{PFGE analysis}

Genomic DNA samples of the isolates were prepared as described by Vela et al. (2000) with modifications. Bacterial growth was obtained on THB incubated at $25^{\circ} \mathrm{C}$ for $24 \mathrm{~h}$ and washed 3 times with buffer $(10 \mathrm{mM}$ Tris- $\mathrm{HCl}, 10 \mathrm{mM}$ EDTA, $10 \mathrm{mM}$ EGTA, $1 \mathrm{M} \mathrm{NaCl}[\mathrm{pH}$ 8]). After centrifugation (3500 $\times g$ for $10 \mathrm{~min}$ ), the supernatant was adjusted to an optical density of 2.0 at $610 \mathrm{~nm}$. The suspension was

Table 1. Lactococcus garvieae. Strain isolates from freshwater, brackish water and seawater and other sources used in this study and their phenotype and genotypic characteristics. Location is by county in Taiwan (ST: southern Taiwan; CT: central Taiwan; NT: northern Taiwan) or by country. Separate entries in relation to county or country indicate that isolates were collected from different sites within the jurisdiction

\begin{tabular}{|c|c|c|c|c|c|c|}
\hline \multirow[t]{2}{*}{ Source and host species } & \multirow{2}{*}{$\begin{array}{l}\text { Year of } \\
\text { isolation }\end{array}$} & \multirow{2}{*}{$\begin{array}{l}\text { No. of } \\
\text { strains }\end{array}$} & \multirow[t]{2}{*}{ Location } & \multirow[t]{2}{*}{ Phenotype } & \multicolumn{2}{|c|}{ Pulsotype } \\
\hline & & & & & Apa I & Sma I \\
\hline \multicolumn{7}{|l|}{ Freshwater } \\
\hline \multirow{9}{*}{$\begin{array}{l}\text { Giant freshwater prawn Macrobrachium } \\
\text { rosenbergii }\end{array}$} & 1999 & 1 & Pingtung, ST & $\mathrm{KG}+$ & A5 & S5 \\
\hline & 1999 & 1 & Pingtung, ST & $\mathrm{KG}-$ & A6 & $\mathrm{S} 6$ \\
\hline & 1999 & 1 & Pingtung, ST & $\mathrm{KG}-$ & A7 & \\
\hline & 2003 & 1 & Pingtung, ST & KG- & $\mathrm{A} 11 \mathrm{~b}$ & $\mathrm{~S} 7$ \\
\hline & 2003 & 1 & Pingtung, ST & KG- & A8 & S8 \\
\hline & 2003 & 1 & Pingtung, ST & KG- & A9 & S9 \\
\hline & 2003 & 1 & Pingtung, ST & KG- & A10 & $\mathrm{S} 10$ \\
\hline & 2003 & 1 & Pingtung, ST & KG- & A10 & $\mathrm{S} 10$ \\
\hline & 2003 & 1 & Pingtung, ST & KG- & A10 & $\mathrm{S} 10$ \\
\hline Tilapia Oreochromis niloticus & 2002 & 2 & Chiayi, ST & KG- & A1a & S1a \\
\hline Bullfrog Rana catesbeiana & 2002 & 1 & Pingtung, ST & $\mathrm{KG}+$ & A3 & S3 \\
\hline Japanese eel Anguilla japonica & 2005 & 1 & Yunlin, CT & KG- & A1a & S1a \\
\hline C1ªllowtail Seriola quinqueradiata & Unknown & 1 & Japan & $\mathrm{KG}-$ & A11a & $\mathrm{S} 11$ \\
\hline $\mathrm{C} 2^{\mathrm{b}} /$ Yellowtail & Unknown & 1 & Japan & $\mathrm{KG}-$ & $\mathrm{A} 11 \mathrm{~b}$ & $\mathrm{~S} 11$ \\
\hline $\mathrm{C} 3^{\mathrm{C}} /$ Yellowtail & Unknown & 1 & Japan & $\mathrm{KG}+$ & $\mathrm{A} 11 \mathrm{C}$ & $\mathrm{S} 12$ \\
\hline \multicolumn{7}{|l|}{ Brackish water } \\
\hline \multirow[t]{12}{*}{ Grey mullet Mugil cephalus } & 2002 & 7 & Chiayi, ST & KG- & A1a & S1a \\
\hline & 2003 & 4 & Chiayi, ST & KG- & A1a & S1a \\
\hline & 2003 & 10 & Tainan, ST & $\mathrm{KG}-$ & A1a & S1a \\
\hline & 2004 & 11 & Chiayi, ST & $\mathrm{KG}-$ & A1a & S1a \\
\hline & 2004 & 2 & Yunlin, CT & KG- & A1a & S1a \\
\hline & 2004 & 2 & Tainan, ST & $\mathrm{KG}-$ & A1a & S1a \\
\hline & 2005 & 1 & Chiayi, ST & KG- & $\mathrm{A} 1 \mathrm{~b}$ & $\mathrm{~S} 1 \mathrm{~b}$ \\
\hline & 2005 & 7 & Chiayi, ST & KG- & A1a & S1a \\
\hline & 2005 & 1 & Yunlin, CT & KG- & A1a & $\mathrm{S} 1 \mathrm{a}$ \\
\hline & 2005 & 1 & Yunlin, CT & $\mathrm{KG}-$ & $\mathrm{A} 2$ & $\mathrm{~S} 2$ \\
\hline & 2006 & 6 & Chiayi, ST & $\mathrm{KG}-$ & A1a & $\mathrm{S} 1 \mathrm{a}$ \\
\hline & 2006 & 2 & Yunlin, CT & $\mathrm{KG}-$ & A1a & S1a \\
\hline \multirow[t]{3}{*}{ Basket mullet Chelon alatus } & 2003 & 1 & Chiayi, ST & KG- & A2 & $\mathrm{S} 2$ \\
\hline & 2004 & 1 & Chiayi, ST & $\mathrm{KG}-$ & A1a & S1a \\
\hline & 2006 & 1 & Chiayi, ST & KG- & A1a & S1a \\
\hline Borneo mullet Chelon macrolepis & 2005 & 1 & Chiayi, ST & $\mathrm{KG}-$ & A1a & S1a \\
\hline \multicolumn{7}{|l|}{ Seawater } \\
\hline \multirow[t]{2}{*}{ Yellowfin seabream Acanthopagrus latus } & 2002 & 1 & Chiayi, ST & KG- & A1a & S1a \\
\hline & 2005 & 1 & Chiayi, ST & KG- & A1a & S1a \\
\hline Grouper Epinephelus coioides & 2002 & 1 & Pingtung, ST & KG- & A1a & S1a \\
\hline \multicolumn{7}{|l|}{ Other sources } \\
\hline ATCC43921\%/Cattle & 1984 & 1 & UK & KG- & A12 & $\mathrm{S} 13$ \\
\hline Human blood & 2003 & 1 & Taoyuan, NT & $\mathrm{KG}-$ & $\mathrm{A} 4$ & $\mathrm{~S} 4$ \\
\hline Squid muscle & 2003 & 1 & Taoyuan, NT & KG- & A4 & $\mathrm{S} 4$ \\
\hline \multicolumn{7}{|c|}{$\begin{array}{l}{ }^{\mathrm{a}} \mathrm{L} \text {. garvieae with complete capsular phenotype } \\
{ }^{\mathrm{b}} \mathrm{L} \text {. garvieae with micro-capsular phenotype } \\
{ }^{\mathrm{c}} \mathrm{L} \text {. garvieae with non-capsular phenotype } \\
{ }^{\mathrm{d}} \text { American Type Culture Collection }\end{array}$} \\
\hline
\end{tabular}


mixed with an equal volume of $2 \%$ low-meltingtemperature agarose (BioWhittaker). Agarose blocks were cast and incubated overnight at $37^{\circ} \mathrm{C}$ in $10 \mathrm{ml}$ lysis buffer (0.5 M EDTA, pH 8.0, 1\% sodium lauryl sarcosine and lysozyme at $5 \mathrm{mg} \mathrm{ml}^{-1}$ ). On the next day, the buffer was replaced with a $10 \mathrm{ml}$ solution (0.5 M EDTA at pH 8.0 and $1 \%$ sodium lauryl sarcosine) containing $2.5 \mathrm{mg}$ Proteinase $\mathrm{K}$ (Sigma) $\mathrm{ml}^{-1}$ and the blocks were incubated at $50^{\circ} \mathrm{C}$ for $48 \mathrm{~h}$. Then the blocks were washed 4 times for $1 \mathrm{~h}$ with $15 \mathrm{ml}$ Tris-EDTA (TE) buffer $(10 \mathrm{mM}$ Tris- $\mathrm{HCl}$ and 1 mM EDTA). The plugs were stored in TE buffer at $4^{\circ} \mathrm{C}$ until use. The experiment was performed in triplicate for each strain to confirm PFGE profiles. The DNA plugs used restriction enzyme digestion with $50 \mathrm{U}$ of either Apa I (New England BioLabs) or Sma I (New England BioLabs) at $25^{\circ} \mathrm{C}$ for $6 \mathrm{~h}$ and were subsequently loaded onto a $1 \%$ agarose gel (Pulsed Field Certified Agarose; Bio-Rad). The low range PFG marker (New England BioLabs) was used as a size marker. PFGE was performed with CHEF Mapper system (Bio-Rad) at $14^{\circ} \mathrm{C}$ for $21 \mathrm{~h}$ after Apa I digestion and $20.18 \mathrm{~h}$ after Sma I digestion at $6 \mathrm{~V} \mathrm{~cm}^{-1}$. Pulse time was then ramped from 0.1 to $21 \mathrm{~s}$ for Apa I digestion and from 0.3 to $12.5 \mathrm{~s}$ for SmaI digestion. Next, gels were stained with ethidium bromide for $30 \mathrm{~min}$, rinsed with distilled water and photographed under UV light. Restriction fragments of each profile were analyzed using Bio-
Profil Bio-1D (v. 11.9) (Vilber lourmat). Finally, a dendrogram was constructed based on the unweighted average pair group method with arithmetic mean (UPGMA) analysis.

\section{Challenge experiment}

Based on the PFGE results, Lactococcus garvieae strains were used for virulence testing in tilapia (60 \pm $5 \mathrm{~g}$, mean $\pm \mathrm{SD})$, grey mullet $(35 \pm 4 \mathrm{~g})$ and giant freshwater prawns $(26 \pm 3 \mathrm{~g})$. Healthy grey mullet and tilapia were obtained from a farm in Chai-Yi and Tainan, Taiwan, respectively, and held at a density of 100 fish in a continuously aerated $500 \mathrm{l}$ aquarium containing $450 \mathrm{l}$ of water at approximately $25^{\circ} \mathrm{C}$ for $7 \mathrm{~d}$ until they were acclimatized. The fish were fed twice daily with commercial fish pellets and waste was removed daily. Healthy prawns were held at a density of 100 prawns in continuously aerated $400 \mathrm{l}$ aquaria containing $300 \mathrm{l}$ of fresh water at approximately $25^{\circ} \mathrm{C}$ for $7 \mathrm{~d}$ until they had been acclimatized to laboratory conditions. They were fed twice daily with commercial prawn pellets and waste was removed daily. The $L$. garvieae strains used in the challenges are listed in Table 2. Fish were anaesthetized prior to inoculation using benzocaine (Sigma). Tilapia $(\mathrm{n}=8)$ were injected intraperitoneally (i.p.) with $0.1 \mathrm{ml}\left(10^{8} \mathrm{CFU}\right)$ of the live bacte-

Table 2. Phenotypes, pulsotypes and mortality of fishes challenged with different bacterial isolates in this study. Data in the same column with different letters denote significant differences according to chi-square multiple proportions $(\mathrm{p}<0.05)$. No mortality was observed in control groups. Mortality is no. of dead animals/no. of animals used. 'Prawn' is the giant freshwater prawn. Mortality data in the same column followed by letters not in common are significantly different $(p<0.05)$. -: not resolvable; nd: no data (not done)

\begin{tabular}{|c|c|c|c|c|c|c|c|}
\hline \multirow[t]{2}{*}{ Strain } & \multirow[t]{2}{*}{ Country } & \multirow[t]{2}{*}{ Source } & \multirow[t]{2}{*}{ Phenotype } & \multirow[t]{2}{*}{ Pulsotype } & \multicolumn{3}{|c|}{ Mortality- } \\
\hline & & & & & Grey mullet & Tilapia & Prawn \\
\hline FLG15 & Taiwan & Grey mullet & KG- & A1a/S1a & $9 / 10^{b}$ & $6 / 8$ & nd \\
\hline FLG6 & Taiwan & Tilapia & $\mathrm{KG}-$ & A1a/S1a & $10 / 10^{b}$ & $6 / 8$ & $7 / 10^{\mathrm{a}, \mathrm{b}}$ \\
\hline FLG58 & Taiwan & Grey mullet & $\mathrm{KG}-$ & $\mathrm{A} 1 \mathrm{~b} / \mathrm{S} 1 \mathrm{~b}$ & $10 / 10^{\mathrm{b}}$ & $4 / 8$ & $10 / 10^{\mathrm{a}}$ \\
\hline FLG31 & Taiwan & Basket mullet & $\mathrm{KG}-$ & A2/S2 & $2 / 10^{\mathrm{a}}$ & $5 / 8$ & $2 / 10^{\mathrm{b}}$ \\
\hline FLG16 & Taiwan & Bullfrog & $\mathrm{KG}+$ & $\mathrm{A} 3 / \mathrm{S} 3$ & $4 / 10^{\mathrm{a}, \mathrm{b}}$ & $3 / 8$ & $3 / 10^{\mathrm{a}, \mathrm{b}}$ \\
\hline 92057 & Taiwan & Human blood & $\mathrm{KG}-$ & $\mathrm{A} 4 / \mathrm{S} 4$ & $1 / 10^{\mathrm{a}}$ & $3 / 8$ & $2 / 10^{\mathrm{b}}$ \\
\hline MR1 & Taiwan & Prawn & $\mathrm{KG}+$ & A5/S5 & nd & $0 / 8$ & $7 / 10^{\mathrm{a}, \mathrm{b}}$ \\
\hline MR5 & Taiwan & Prawn & $\mathrm{KG}-$ & A6/S6 & $4 / 10^{\mathrm{a}, \mathrm{b}}$ & $0 / 8$ & $3 / 10^{\mathrm{a}, \mathrm{b}}$ \\
\hline MR6 & Taiwan & Prawn & $\mathrm{KG}-$ & A7/- & nd & $0 / 8$ & $10 / 10^{\mathrm{a}}$ \\
\hline MR10 & Taiwan & Prawn & $\mathrm{KG}-$ & $\mathrm{A} 11 \mathrm{~b} / \mathrm{S} 7$ & nd & $4 / 8$ & $9 / 10^{\mathrm{a}, \mathrm{b}}$ \\
\hline MR12 & Taiwan & Prawn & $\mathrm{KG}-$ & A8/S8 & nd & $0 / 8$ & $6 / 10^{\mathrm{a}, \mathrm{b}}$ \\
\hline MR18 & Taiwan & Prawn & $\mathrm{KG}-$ & A9/S9 & $4 / 10^{\mathrm{a}, \mathrm{b}}$ & $3 / 8$ & $5 / 10^{\mathrm{a}, \mathrm{b}}$ \\
\hline MR23 & Taiwan & Prawn & $\mathrm{KG}-$ & $\mathrm{A} 10 / \mathrm{S} 10$ & nd & $1 / 8$ & $4 / 10^{\mathrm{a}, \mathrm{b}}$ \\
\hline $\mathrm{C} 1$ & Japan & Yellowtail & $\mathrm{KG}-$ & A11a/S11 & $10 / 10^{\mathrm{b}}$ & $6 / 8$ & $8 / 10^{a, b}$ \\
\hline $\mathrm{C} 2$ & Japan & Yellowtail & $\mathrm{KG}-$ & $\mathrm{A} 11 \mathrm{~b} / \mathrm{S} 11$ & nd & $2 / 8$ & $4 / 10^{\mathrm{a}, \mathrm{b}}$ \\
\hline $\mathrm{C} 3$ & Japan & Yellowtail & $\mathrm{KG}+$ & $\mathrm{A} 11 \mathrm{c} / \mathrm{S} 12$ & $1 / 10^{\mathrm{a}}$ & $0 / 8$ & $3 / 10^{\mathrm{a}, \mathrm{b}}$ \\
\hline ATCC 43921 & UK & Cattle & $\mathrm{KG}-$ & $\mathrm{A} 12 / \mathrm{S} 13$ & nd & nd & nd \\
\hline
\end{tabular}


ria. Grey mullet $(n=10)$ were also injected i.p. with $0.1 \mathrm{ml}\left(10^{7} \mathrm{CFU}\right)$ of the live bacteria. Giant freshwater prawns $(n=10)$ were injected intramuscularly (i.m.) with $0.1 \mathrm{ml}\left(10^{7} \mathrm{CFU}\right)$ of the live bacteria. Grey mullet $(\mathrm{n}=10)$, tilapia $(\mathrm{n}=8)$ and prawns $(\mathrm{n}=10)$ in the control group were inoculated with sterile saline. After injection, each group was maintained separately in an $80 \mathrm{l}$ aquarium at 25 to $26^{\circ} \mathrm{C}$. The fish and prawns were monitored continuously for morbidity and mortality and sampled for bacteriological analyses and PCR to confirm identification of the bacterial isolates. The strains were re-isolated from dead fish and prawns on THA at $25^{\circ} \mathrm{C}$ for $48 \mathrm{~h}$. The experiment was terminated at $10 \mathrm{~d}$ post-inoculation. Statistical analyses of the mortality of pulsotype variants of $L$. garvieae were performed by chi-square multiple proportions.

\section{RESULTS}

\section{PCR and agglutination profiles}

All strains used in this study revealed Gram-positive ovoid cells forming short chains that exhibited $\alpha$ haemolysis and gave the expected 1100-bp PCR amplification product that is specific to Lactococcus garvieae (data not shown). Briefly, all 76 Taiwanese strains were identified as L. garvieae. Moreover, $L$. garvieae $\mathrm{KG}+$ and $\mathrm{KG}-$ phenotypes are shown in Table 1. Only 2 L. garvieae strains, FLG16 (from bullfrog) and MR1 (from giant freshwater prawn), had $\mathrm{KG}+$ phenotypes that can agglutinate with rabbit anti-KG+ phenotype antiserum. Moreover, rabbit antiserum raised against encapsulated Japanese C1 isolate (KG- phenotype) only agglutinated with 10 Taiwanese isolates (data not shown).

\section{PFGE analysis}

Apa I and Sma I restriction digestion of chromosomal DNA from 80 Lactococcus garvieae strains (76 Taiwanese strains, 3 Japanese strains and reference strain ATCC 43921) yielded 9 to 16 and 13 to 21 wellresolved genomic DNA bands, ranging in size from approximately 25 to 291 and 22 to $272 \mathrm{~kb}$, respectively (Fig. 1). The PFGE results for all investigated strains are summarized in Table 1 . The 76 strains isolated in Taiwan were classified into 11 (from A1 to A11) and 10 (from S1 to S10) pulsotypes by Apa I and SmaI, respectively. However, MR6 was not amenable to SmaI digestion, resulting in insuffi- ciently resolved DNA fragments. Of the 74 Taiwanese strains from diseased, cultured, aquatic animals, 61 strains from grey mullet (subtype A1a/S1a, $\mathrm{n}=52)$, basket mullet $(\mathrm{n}=2)$, Borneo mullet $(\mathrm{n}=1)$, tilapia $(n=2)$, grouper $(n=1)$, yellowfin seabream $(n=2)$ and Japanese eel $(n=1)$ were grouped in the predominant pulsotype A1a/S1a. The pulsotype $\mathrm{A} 1 \mathrm{~b} / \mathrm{S} 1 \mathrm{~b}$ was isolated from a single grey mullet. One isolate each from grey mullet and basket mullet were pulsotype A2/S2. Pulsotype A3/S3 was found in the bullfrog isolate. Additionally, the isolates from the human patient and raw squid muscle both had pulsotype A4/S4. The 9 isolates from giant freshwater prawn showed greater variation in PFGE patterns (A5 to A11 and S5 to S10) than isolates from grey mullet. However, L. garvieae strain MR10 from the giant freshwater prawn had the same pulsotype A11b by ApaI as did the L. garvieae strains from yellowtail from Japan, yet had a different SmaI pulsotype in PFGE. The dendrogram obtained with 12 and 13 different patterns after UPGMA clustering by Apa I and Sma I, respectively, are also illustrated in Fig. 1.

\section{Challenge experiment}

In the challenge studies, grey mullet exhibited clinical signs of lactococcosis (e.g. anorexia, haemorrhage, dark pigmentation, erratic swimming and clouding of the cornea) and mass mortality during the $10 \mathrm{~d}$ after inoculation with Lactococcus garvieae. The prawns showed opaque and whitish muscles. However, tilapia were observed to have less marked clinical signs. Additionally, a significant difference was found in the mortality levels of grey mullet and prawns challenged with different bacterial isolates, but this was not seen in tilapia. The mortality in fish and prawns challenged with L. garvieae is summarized in Table 2 . The same bacteria re-isolated from moribund and dead fish and prawns were identified as L. garvieae by PCR. No mortality and bacteria were detected in control groups.

High mortality (90 to $100 \%$ ) was observed in the grey mullet challenged with pulsotype A1a/S1a (isolates FLG6, FLG15), A1b/S1b (isolate FLG58) and A11/S11 pulsotype (Japanese isolate C1, Lactococcus garvieae with complete capsular phenotype). Conversely, pulsotypes A2/S2 (isolate FLG31), A4/S4 (isolate 92057) and A11/S12 (Japanese isolate C3, L. garvieae with non-capsular phenotype) caused low mortality (10 to $20 \%$ ). Compared with grey mullet, lower mortality (50 to $75 \%$ ) was observed in the 
tilapia challenged with pulsotypes A1a/S1a, A1b/S1b and A11/S1. Isolates FLG16 (A3/S3, from bullfrog) and 92057 (A4/S4, from human) caused low mortality $(37.5 \%)$ in tilapia. Further, the Japanese strain C1 with a highly developed capsule (KG- phenotype cells) was more virulent to the grey mullet, tilapia and giant freshwater prawns than were strains C2 with micro-capsule (KG- phenotype cells) and C3
A

Source

Cow

Human

Basket mullet

Giant freshwater prawn

Yellowtail

Yellowtail

Yellowtail

Giant freshwater prawn

Bullfrog

Giant freshwater prawn

Giant freshwater prawn

Giant freshwater prawn

Giant freshwater prawn

Grey mullet

Grey mullet

Giant freshwater prawn

B

$\begin{array}{lcc}\text { Source } & \text { Country } & \begin{array}{c}\text { Pulsotype } \\ \text { Marker }\end{array} \\ \text { Cow } & \text { United Kingdom } & \text { S13 } \\ \text { Yellowtail } & \text { Japan } & \text { S11 } \\ \text { Yellowtail } & \text { Japan } & \text { S11 } \\ \text { Yellowtail } & \text { Japan } & \text { S12 } \\ \text { Human } & \text { Taiwan } & \text { S4 } \\ \text { Giant freshwater prawn } & \text { Taiwan } & \text { S5 } \\ \text { Giant freshwater prawn } & \text { Taiwan } & \text { S8 } \\ \text { Grey mullet } & \text { Taiwan } & \text { S1a } \\ \text { Grey mullet } & \text { Taiwan } & \text { S1b } \\ \text { Basket mullet } & \text { Taiwan } & \text { S2 } \\ \text { Giant freshwater prawn } & \text { Taiwan } & \text { S7 } \\ \text { Giant freshwater prawn } & \text { Taiwan } & \text { S6 } \\ \text { Bullfrog } & \text { Taiwan } & \text { S3 } \\ \text { Giant freshwater prawn } & \text { Taiwan } & \text { S9 } \\ \text { Giant freshwater prawn } & \text { Taiwan } & \text { S10 }\end{array}$

Size (kbp)

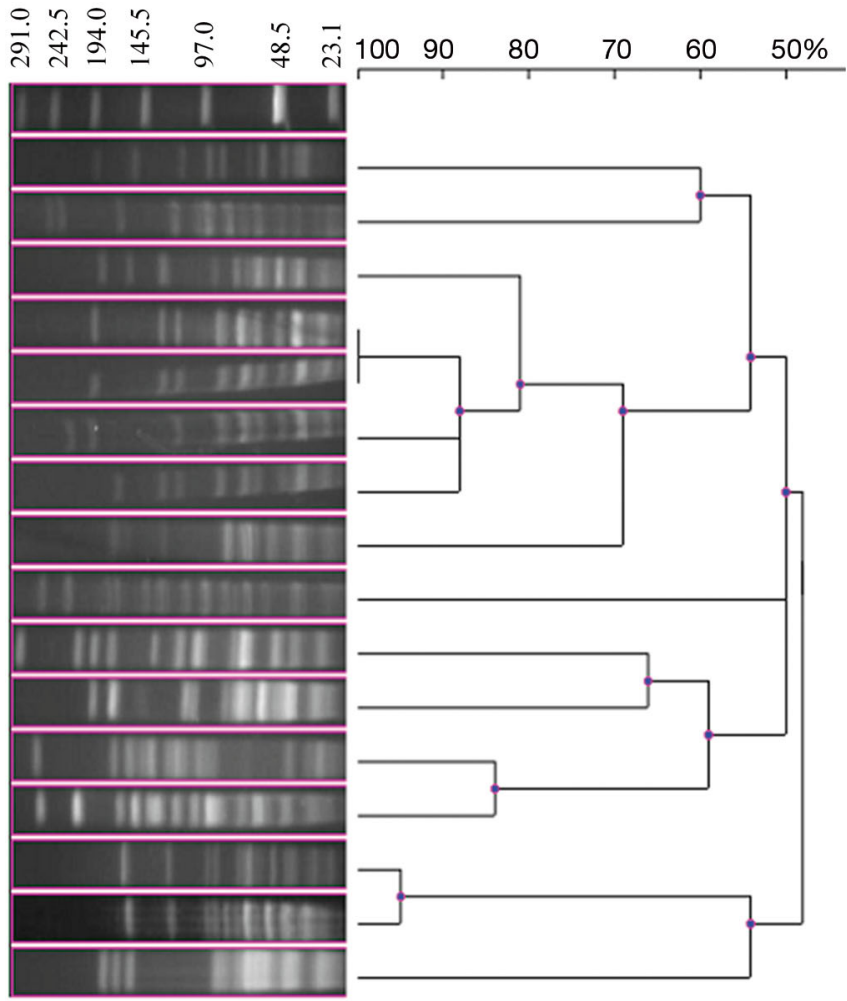

Size (kbp)

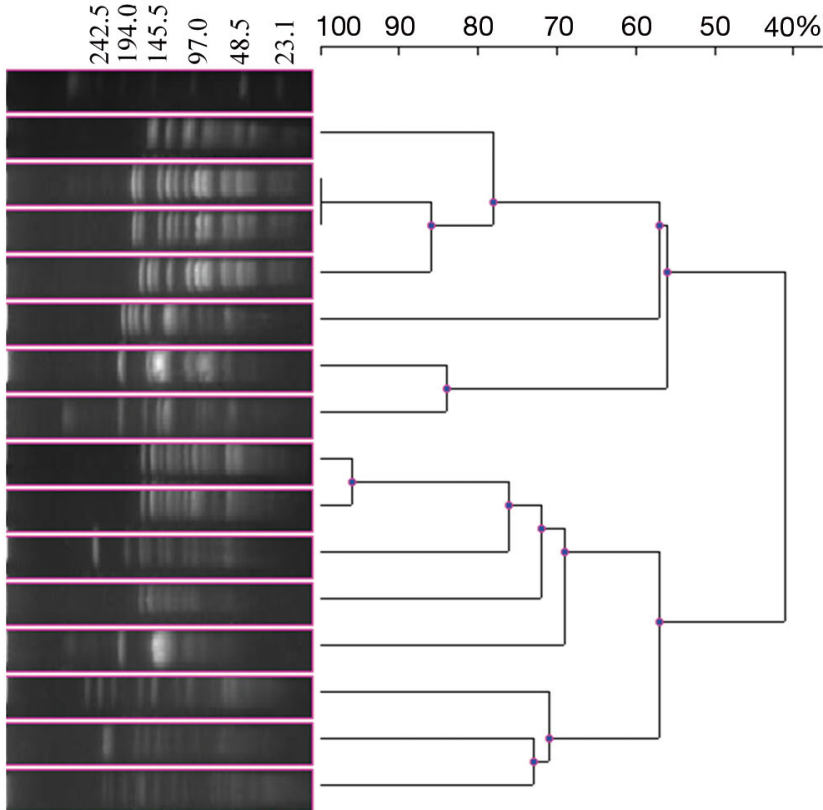

Fig. 1. Lactococcus garvieae. Pulsotype and dendrogram for (A) ApaI and (B) SmaI obtained for isolates of L. garvieae from Taiwan and Japan and for L. garvieae ATCC 43921 
without capsule (KG+ phenotype cells). Additionally, L. garvieae isolates MR1, MR5, MR6, MR10, MR12, MR18 and MR23 from giant freshwater prawns caused low mortality ( 0 to $50 \%$ ) in tilapia. The virulences of MR5 and MR18, the only prawn isolates used in grey mullet challenges, were not different in either grey mullet or giant freshwater prawns. Mortalities of 30 to $100 \%$ were seen in giant freshwater prawns after they were challenged with different prawn isolates but the differences were not significant. L. garvieae isolates FLG58 from grey mullet and MR6 from prawns showed higher virulence to prawns than the L. garvieae isolate FLG31 from basket mullet and the human isolate 92057. Additionally, no significant difference in mortality was observed in tilapia challenged with different bacterial isolates.

\section{DISCUSSION}

Lactococcus garvieae infections were responsible for disease outbreaks during the hot season in farms that breed giant freshwater prawns, grey mullet and rainbow trout in Taiwan (Chen et al. 2001, 2002, Chang et al. 2002). However, L. garvieae infection was also observed recently in other cultured aquatic animals in Taiwan (Yunlin County Animal Disease Control Center 2006); thus, it is very important to investigate the relationship between isolates from these farmed aquatic animals. In this study, $L$. garvieae infection has been confirmed in more than 9 aquatic animals in Taiwan, and the study represents the first confirmed report of L. garvieae infection in grouper, yellowfin seabream, basket mullet, Borneo mullet and bullfrog. PFGE has been used to evaluate the genetic relationships among Taiwanese L. garvieae isolates from different hosts. Several investigators have demonstrated the feasibility of applying PFGE to differentiate between strains of L. garvieae (Kawanishi et al. 2005, 2006). The PFGE results presented here indicated a high level of genetic homogeneity among the strains from diseased cultured fish species in Yunlin County, located in central Taiwan, as well as in Chiayi and Tainan counties, located in southern Taiwan where the A1a/S1a pulsotype was the most common strain. This demonstrates a clonal dissemination of $L$. garvieae in grey mullet, tilapia, grouper, yellowfin seabream, Borneo mullet and Japanese eel in central and southern Taiwan. Pulsotype A1a/S1a was not observed in other aquatic animals (bullfrog and giant freshwater prawn) in southern Taiwan, nor in a human in Taiwan.
A1a/S1a was not only the most commonly observed grey mullet PFGE type (accounting for $96.3 \%$ of grey mullet isolates), but also the type obtained during annual outbreaks in grey mullet during the period 2002 to 2006. The difference between pulsotype A1a/S1a and pulsotype A1b/S1b was only one fragment, and the similarity level was higher than $95 \%$. Single strains with pulsotypes A1b/S1b and A2/S2 were isolated from grey mullet and a single strain with pulsotype A2/S2 from basket mullet. Clinical cases associated with Lactococcus garvieae infection in humans have been described in Taiwan, where several patients had a history of consuming seafood, raw fish and squid muscle (Wang et al. 2007). Moreover, a previous study suggested that the consumption of raw seafood during summer months (when $L$. garvieae infections are at the highest) by patients who have underlying gastrointestinal disorders may predispose them to $L$. garvieae infection, as $L$. garvieae has been identified in patients' blood by specific $16 \mathrm{~S}$ rDNA PCR analysis followed by sequencing the products (Wang et al. 2007). The same pulsotype, A4/S4, was isolated from a patient with a history of eating raw squid muscle and from the raw squid muscle samples in this study. A4/S4 was not isolated from the other farmed aquatic animal species sampled in this study. In previous studies by Vela et al. (2000) and Kawanishi et al. (2005), human isolates of $L$. garvieae were not genetically related to those from cultured aquatic animals. The present study showing similarity between human and squid isolates is small and includes only 1 patient in Taiwan. A larger sample size is necessary to more thoroughly investigate these potential risk factors.

Although several studies (Amborski et al. 1983, Elliott et al. 1990, Hung et al. 2008) have described streptococcosis in bullfrogs, Lactococcus garvieae infection has not yet been described in bullfrogs. In the present study, one L. garvieae isolate from a bullfrog displayed a unique pulsotype A3/S3 and was not genetically related to other aquatic animals. Although fish lactococosis has received considerable attention, the genetic characteristics of $L$. garvieae isolated from giant freshwater prawns have seldom been addressed. To our knowledge, this study provides for the first time information on the genetic relationship between L. garvieae isolates from fish and prawns and the potential for epidemiological relationships and disease transmission based on i.p. challenge experiments. L. garvieae isolates from grey mullet, tilapia and giant prawns were able to survive (confirmed by re-isolation of colonies) in all 3 species and cause similar mortality in some cases. 
L. garvieae isolates from giant freshwater prawns exhibited a high genetic diversity by PFGE, with 7 pulsotypes among 9 isolates of $L$. garvieae. Most of the prawn isolates were genetically unrelated to fish isolates, and only the MR10 strain proved to be more genetically related to fish strains than to those isolated from other giant freshwater prawns in this study. Furthermore, this strain also has the same pulsotype A11b by ApaI as does Japanese strain C2 from yellowtail.

Lactococcus garvieae has been divided into nonagglutinating (KG-) and agglutinating (KG+) phenotype cells by using KG+ antiserum (Kitao 1982, Yoshida et al. 1996). The KG- phenotype (nonagglutinating strain against $\mathrm{KG}+$ antiserum) strains are encapsulated and more virulent to fish than the KG+ phenotype strains (Alim et al. 1996). In our study, most of the L. garvieae isolates from Taiwan exhibited KG- phenotype (74/76). Only isolates from 1 bullfrog (FLG16) and 1 giant freshwater prawn (MR1) exhibited the KG+ phenotype. Additionally, most Taiwanese isolates exhibiting the KG- phenotype (64/74) did not agglutinate with anti-sera raised against the Japanese encapsulated isolates. These results also suggest that the antigenic variation noted between the Taiwanese and Japanese isolates is a result of capsular variation (Barnes \& Ellis 2004). Virulence variation in fish associated with a variety of genetic characters of $L$. garvieae is unclear. This study evaluated the virulence of different pulsotype strains in the challenge experiment using grey mullet and tilapia. According to our results, pulsotype A1/S1 (including A1a/S1a and A1b/S1b) and A11a/S11 (Japanese strain $\mathrm{C} 1$ ) displayed high virulence in grey mullet and tilapia. This high virulence by pulsotype A1/S1 of L. garvieae combined with a KG- phenotype, as seen with isolate $\mathrm{C} 1$, suggests $L$. garvieae with pulsotype A1/S1 possesses a highly developed capsule, though this would need to be confirmed. Moreover, capsulated strain C1 exhibited higher virulence to the grey mullet and tilapia than microcapsulated and non-capsulated strains (strains C2 and C3). Similar results have been described previously (Alim et al. 1996, Ooyama et al. 2002). It is also worth noting that the same pulsotypes (A1/S1 and A11a/S11) also gave high mortality in giant freshwater prawns, indicating that these pulsotypes may be highly virulent across different phyla. In contrast, L. garvieae isolates from giant freshwater prawns (pulsotypes A5/S5, A6/S6, A7/-, A8/S8, A9/S9 and A10/S10), bullfrogs (A3/S3), humans (pulsotype A4/ $\mathrm{S} 4$ ) and yellowtail (pulsotype A11c/S12) resulted in low mortality in fish. L. garvieae isolates MR6 and
MR10 from giant freshwater prawns (pulsotypes A7/- and A11b/S7) showed high mortality in the prawns. The MR10 strain proved to be more genetically related to fish strains than to other prawn strains, based on UPGMA analysis, and resulted in higher mortality in tilapia compared with other strains isolated from the giant freshwater prawn. Its virulence in grey mullet unfortunately could not be compared with other prawn strains as only 2 prawn strains, MR5 and MR18, were tested with this fish species. Pulsotype A2/S2 was isolated from grey mullet and basket mullet, but caused low mortality in grey mullet and giant freshwater prawns in the challenge experiment. Pulsotype A2/S2 L. garvieae strain may exhibit weak virulence in grey mullet, which could explain why the A2/S2 pulsotype was only isolated rarely in grey mullet in our study (Table 1).

In conclusion, Lactococcus garvieae from fish, prawns, a bullfrog, raw seafood and a human in Taiwan exhibited 10 pulsotypes. The A1/S1 pulsotype was observed in a range of fish species and displayed strong virulence to fish. Analysis of genetic characteristics indicated that fish and prawn lactococcosis outbreaks were produced by genetically unrelated clones overall. However, one L. garvieae strain isolated from giant freshwater prawns displayed a close genetic relationship with strains from fish by genetic and virulence results, suggesting that a relationship between lactococcosis outbreaks in fish and prawns is possible. The number of isolates from the different fish species other than grey mullet, and over a wider geographic range including regions with prawn culture, needs to be increased to strengthen the above conclusions.

Acknowledgements. The authors thank the National Science Council of Taiwan for financially supporting this research under the contract no. 95-2313-B-020-008MY3 and the Council of Agriculture of Taiwan for financially supporting this research under contract no. 100AT-1.1.8-I-B2.

\section{LITERATURE CITED}

Alim S, Kawai K, Kusuda R (1996) Comparative pathogenicity study on antigenically variant strains of Enterococcus seriolicida. J Fish Dis 19:39-46

Amborski RL, Snider TG, Thune RL, Culley DDJ (1983) A non-hemolytic, group B Streptococcus infection of cultured bullfrogs, Rana catesbeiana, in Brazil. J Wildl Dis 19:180-184

> Barnes AC, Ellis AE (2004) Role of capsule in serotypic differences and complement fixation by Lactococcus garvieae. Fish Shellfish Immunol 16:207-214

Carvalho MG, Vianni MC, Elliott JA, Reeves M, Facklam RR, Teixeira LM (1997) Molecular analysis of Lactococ- 
cus garvieae and Enterococcus gallinarum isolated from water buffalos with subclinical mastitis. Adv Exp Med Biol 418:401-404

Chang P, Lin C, Lee Y (2002) Lactococcus garvieae infection of cultured rainbow trout, Oncorhynchus mykiss. Taiwan and associated biophysical characteristics and histopathology. Bull Eur Assoc Fish Pathol 22:319-327

$>$ Chen SC, Lin YD, Liaw LL, Wang PC (2001) Lactococcus garvieae infection in the giant freshwater prawn Macrobranchium rosenbergii confirmed by polymerase chain reaction and 16S rDNA sequencing. Dis Aquat Org 45: $45-52$

> Chen SC, Liaw LL, Su HY, Ko SC and others (2002) Lactococcus garvieae, a cause of disease in grey mullet, Mugil cephalus L. in Taiwan. J Fish Dis 25:727-732

Devriese LA, Hommez J, Laevens H, Pot B, Vandamme P, Haesebrouck F (1999) Identification of aesculinhydrolyzing streptococci, lactococci, aerococci and enterococci from subclinical intramammary infections in dairy cows. Vet Microbiol 70:87-94

Elliott JA, Facklam RR, Richter CB (1990) Whole-cell protein patterns of nonhemolytic group B, type Ib, streptococci isolated from humans, mice, cattle, frogs, and fish. J Clin Microbiol 28:628-630

> Elliott JA, Collins MD, Pigott NE, Facklam RR (1991) Differentiation of Lactococcus lactis and Lactococcus garvieae from humans by comparison of whole-cell protein patterns. J Clin Microbiol 29:2731-2734

Fefer JJ, Ratzan KR, Sharp SE, Saiz E (1998) Lactococcus garvieae: endocarditis report of a case and review of the literature. Diagn Microbiol Infect Dis 32:127-130

> Hung SW, Wang SL, Tu CY, Tsai YC and others (2008) Antibiotic susceptibility and prevalence of erythromycin ribosomal methylase gene, erm(B) in Streptococcus spp. Vet J 176:197-204

James PR, Hardman SMC, Patterson DLH (2000) Osteomyelitis and possible endocarditis secondary to Lactococcus garvieae: a first case report. Postgrad Med J 76: 301-303

Kawanishi M, Kojima A, Ishihara K, Esaki H and others (2005) Drug resistance and pulsed-field gel electrophoresis patterns of Lactococcus garvieae isolates from cultured Seriola (yellowtail, amberjack and kingfish) in Japan. Lett Appl Microbiol 40:322-328

Kawanishi M, Yoshida T, Yagashiro S, Kijima M and others (2006) Differences between Lactococcus garvieae isolated from the genus Seriola in Japan and those isolated from other animals (trout, terrestrial animals from

Editorial responsibility: Catherine Collins,

Aberdeen, UK
Europe) with regard to pathogenicity, phage susceptibility and genetic characterization. J Appl Microbiol 101: 496-504

Kitao T (1982) The methods for detection of Streptococcus sp., causative bacteria of streptococcal disease of cultured yellowtail (Seriola quinqueradiata). Especially, their cultural, biochemical and serological properties. Fish Pathol 17:17-26

> Li WK, Chen YS, Wann SR, Liu YC, Tsai HC (2008) Lactococcus garvieae endocarditis with initial presentation of acute cerebral infarction in a healthy immunocompetent man. Intern Med 47:1143-1146

> Ooyama T, Hirokawa Y, Minami T, Yasuda H and others (2002) Cell-surface properties of Lactococcus garvieae strains and their immunogenicity in the yellowtail Seriola quinqueradiata. Dis Aquat Org 51:169-177

> Shimahara Y, Huang YF, Tsai MA, Wang PC, Yoshida T, Lee JL, Chen SC (2009) Genotypic and phenotypic analysis of fish pathogen, Nocardia seriolae, isolated in Taiwan. Aquaculture 294:165-171

Tenover FC, Arbeit RD, Goering RV, Mickelsen PA, Murray BE, Persing DH, Swaminathan B (1995) Interpreting chromosomal DNA restriction patterns produced by pulsed-field gel electrophoresis criteria for bacterial strain typing. J Clin Microbiol 33:2233-2239

Vela AI, Vázquez J, Gibello A, Blanco MM and others (2000) Phenotypic and genetic characterization of Lactococcus garvieae isolated in Spain from lactococcosis outbreaks and comparison with isolates of other countries and sources. J Clin Microbiol 38:3791-3795

> Vinh DC, Nichol KA, Rand F, Embil JM (2006) Native-valve bacterial endocarditis caused by Lactococcus garvieae. Diagn Microbiol Infect Dis 56:91-94

Wang CYC, Shie HS, Chen SC, Huang JP and others (2007) Lactococcus garvieae infections in humans: possible association with aquaculture outbreaks. Int J Clin Pract 61:68-73

> Yoshida T, Eshima T, Wada Y, Yamada Y and others (1996) Phenotypic variation associated with an anti-phagocytic factor in the bacterial fish pathogen Enterococcus seriolicida. Dis Aquat Org 25:81-86

Yunlin County Animal Disease Control Center (2006) Bulletin of the aquatic animal disease control. Epidemiol Bull Issue 39-42. Yunlin County Animal Disease Control Center, Taiwan (in Chinese)

Zlotkin A, Eldar A, Ghittino C, Bercovier H (1998) Identification of Lactococcus garvieae by PCR. J Clin Microbiol 36: 983-985

Submitted: September 8, 2011; Accepted: August 9, 2012 Proofs received from author(s): November 14, 2012 